\title{
DỰ BÁO TÁC ĐộNG CỦA CÔNG NGHIỆP 4.0 ĐẾN VIỆC LÀM CỦA SINH VIÊN ĐẠI HỌC CÔNG NGHIỆP TP.HCM SAU KHI TỐT NGHIỆP
}

\author{
PHAN HỒNG HẢI, ĐOÀN HÙNG CƯỜNG \\ Truờng Đại học Công Nghiệp thành phố Hồ Chí Minh; \\ phanhonghai@iuh.edu.vn; doanhungcuong@iuh.edu.vn
}

Tóm tắt. Tự động hóa trong Công nghiệp 4.0 mang lại năng lực cạnh tranh mạnh mẽ và sẽ thu hút thêm nhiều doanh nghiệp tham gia cuộc cách mạng này. Kết quả là nhu cầu nhân lực sẽ giảm mạnh trong các việc làm có quy trình thủ tục cố định, tiện thay thế bằng máy móc. Mặt khác, sự xuất hiện nhiều công nghệ mới sẽ làm gia tăng nhu cầu nhân lực trong các công việc mang tính phi thủ tục, linh hoạt và sáng tạo. Dự báo tình hình việc làm của sinh viên tốt nghiệp từ Đại học Công nghiệp TP. Hồ Chí Minh dưới tác động của Công nghiệp 4.0 cho thấy nhà trường cần có định hướng rõ theo xu hướng nhu cầu mới về cơ cấu lao động, xây dựng chương trình đào tạo nhân lực đặt trọng tâm vào khả năng thực hiện các công việc phi thủ tục, sáng tạo, kỹ năng lãnh đạo, thích ứng các thay đổi trong môi trường mang tính mở, đảm bảo sinh viên tốt nghiệp đạt các bậc kỹ năng cao, góp phần cải thiện nguồn nhân lực quốc gia kịp thích ứng thời đại mới. Từ khóa. Công nghiệp 4.0, công việc theo thủ-tục, công việc phi-thủ-tục, Đại học Công nghiệp TP. Hồ Chí Minh

\section{FORECASTING THE IMPACT OF INDUSTRY 4.0 TO THE GRADUATES OF INDUSTRIAL UNIVERSITY OF HO CHI MINH CITY}

\begin{abstract}
Automation in Industry 4.0 brings about strong competitiveness, which will attract more businesses to join this revolution. As a result, the demand for human resources will fall drastically for automatable jobs which involve fixed procedures or rote memorization that can be performed by machines. Meanwhile, the emergence of new technologies will increase the demand for manpower in non-procedural tasks, which require flexibility and creativity. The forecasted employment outlook of graduates from the Industrial University of Ho Chi Minh City under the impact of Industry 4.0 shows that the university needs to have a clear orientation toward the structural shifts in labour demand, establish a human resource training program that focuses on the ability to carry out non-routine tasks, while fostering creativity, leadership skills, adaptability to changes in open work environments, thus ensuring graduates achieve higher skill levels and contribute to the national labour market to keep up with the coming era.
\end{abstract}

Keywords. Industrial revolution 4.0, routine task, non-routine task, Industrial University of Ho Chi Minh city.

\section{GIỚI THIÊ.U}

Cách mạng Công nghiệp lần đầu với công cụ máy hơi nước làm năng suất tăng đột biến; Cách mạng Công nghiệp lần hai với điện năng tạo nền sản xuất đại công nghiệp; Cách mạng Công nghiệp lần thứ ba xuất hiện máy móc có "bộ não" máy vi tính không chỉ tính toán nhanh mà bắt đầu có nhận thức nhân tạo; Ngày nay Cách mạng công nghiệp lần thứ tư (gọi tắt là Công nghiệp 4.0) được dự đoán sẽ tạo các thay đổi lớn gấp bội lần bởi sự xuất hiện và kết hợp đồng thời của hàng loạt công nghệ mới như High-Tech Sensors, AI, IoT, 3D Print, VR, AR, iCloud, BigData... Hàng tỉ con người kết nối hệ thống mạng kỹ thuật số sẽ sớm thúc đẩy sự thay đối sâu và rộng phương thức sản xuất, ngành nghề, kinh tế và xã hội, tạo ra hàng loạt cơ hội và cả rủi ro mới.

Khi công nghiệp hóa đi cùng với tự động hóa, nhiều vị trí làm việc trước đây của con người sẽ bị thay thế bởi máy móc hoặc biến mất bởi ngành nghề bị lỗi thời, hết hữu dụng. Điều này gây lo lắng đến mức xuất hiện nhiều cảnh báo từ nhiều doanh nhân và nhà trí thức hàng đầu thế giới như Bill Gates, Elon Musk, and Stephen Hawking (Quincy Larson, 2017). Tuy vậy, theo nhiều nhà nghiên cứu, nhiều công việc, ngành nghề mới sẽ ra đời tạo nhiều việc làm mới. Gaggl and Wright (2017) cho biết IT làm tăng việc làm bán sỉ, 
bán lẻ, công nghiệp tài chính. Mann and Puttman (2017) dựa trên phân tích về tác động của các bằng sáng chế cho thấy tự động hóa tuy làm giảm các việc làm thuộc ngành sản xuất, nhưng tăng các việc làm của ngành dịch vụ. Akerman, Gaarder, and Mogstad (2015) xác định Internet làm tăng việc làm có kỹ năng mà không ảnh hưởng đến việc làm ít kỹ năng. Còn theo Bessen (2016) thì tự động hóa sẽ tác động gia tăng tổng lượng việc làm, đồng thời làm giảm việc làm ở khu vực thu nhập thấp. Tương tự, theo nghiên cứu của Autor and Salomons (2017) thì việc gia tăng hiệu suất dẫn đến gia tăng tổng lượng việc làm nhờ công cụ tân tiến, xã hội thịnh vượng hơn sẽ làm tăng nhu cầu về hàng hóa và lao động.

Kết quả nói chung là phát triển tự động hóa làm tổng lượng việc làm tăng và giảm tỉ lệ thất nghiệp chung. Tuy nhiên, kết cục tốt như vậy không phải diễn ra ở mọi khu vực, mọi quốc gia, mà chỉ xảy ra ở những nơi bắt kịp, thích ứng được sự thay đổi. Sự thay đổi nhanh các nhu cầu và sự xuất hiện các nhu cầu mới buộc các doanh nghiệp cũng phải thay đổi nhanh chóng, cập nhật công nghệ để cạnh tranh, tham gia mạnh hơn nữa vào quá trình tự động hóa, từ đó tạo nên một áp lực chưa từng có buộc lực lượng lao động muốn giữ việc làm sẽ phải "chạy đua" để thích ứng các yêu cầu kiến thức, kỹ năng mới trong công việc mới.

Trong cuộc đua của người lao động với máy tự động để kịp cập nhật các kiến thức, kỹ năng mới, vai trò của các tổ chức đào tạo giáo dục đứng ở vị trí hàng đầu. Các trường đại học, cao đẳng là nơi cung cấp kiến thức chuyên nghiệp ở các bậc kỹ năng, nhận thức cao nên cũng là nơi phải dẫn đầu trong cuộc đua này. Để giành phần thắng về người lao động, các nhà giáo dục và đào tạo phải định hướng đúng cho chương trình đào tạo, hướng người học thích ứng với các công việc trong Công nghiệp 4.0.

Là trường đại học thuộc tốp đầu của Bộ Công thương, với sứ mạng cung ứng lực lượng lao động tiên tiến có năng lực ứng dụng cao, phù hợp với nhu cầu thị trường lao động, Đại học Công nghiệp TP. Hồ Chí Minh (Tến viết tắt là IUH) được kỳ vọng trở thành một trong những nơ tốt nhất trong việc cung ứng sinh viên tốt nghiệp có việc làm phù hợp, hiệu quả trong tương lai Công nghiệp 4.0.

Để xem xét tính phù hợp của kết quả đào tạo với khả năng đáp ứng công việc trong Công nghiệp 4.0, kế thừa phương pháp nghiên cứu của nhiều chuyên gia quốc tế về lao động và việc làm trong Công nghiệp 4.0, nghiên cứu này tập trung trả lời bốn câu hỏi chính: Thứ nhất, xác định hiện trạng cơ cấu việc làm của sinh viên tốt nghiệp từ IUH phân chia theo công việc theo-thủ-tục hay phi-thủ-tục và xu hướng tiếp diễn của cơ cấu này? Thứ hai, loại việc làm theo-thủ-tục (routine task) hay phi-thủ-tục (non-routine task) sẽ chịu tác động tiêu cực hơn khi tự động hóa phát triển? Thứ ba, xu hướng phát triển cơ cấu việc làm ở các quốc gia đi trước trong Công nghiệp 4.0 ra sao? Thứ tư, huớng đi nào phù hợp để thích ứng với Công nghiệp 4.0 trong giáo dục đại học nói chung và tại IUH nói riêng?

Để giải đáp các câu hỏi trên, trước hết nhóm tác giả tiến hành xem xét thực trạng công việc của sinh viên sau tốt nghiệp (graduates) từ IUH trong bối cảnh chung của lao động có trình độ và việc làm tương đương ở Việt Nam. Tiếp theo, dự báo cơ cấu việc làm mà sinh viên sau tốt nghiệp từ IUH sẽ có thể đáp ứng được, trong đó chủ yếu phân biệt giữa công việc có tính chất theo-thủ-tục với phi-thủ-tục. Từ đó, so sánh với hướng phát triển nhu cầu loại công việc trong Công nghiệp 4.0 trên thế giới và tại Việt Nam. Kết quả sẽ làm rõ ra sự khác biệt nếu có giữa cơ cấu được dự báo về lao động được đào tạo từ IUH (nếu IUH giữ nguyên chính sách hiện tại) với cơ cấu lao động thích ứng cho Công nghiệp 4.0. Đó là cơ sở cần thiết để định hướng, xây dựng chương trình đào tạo phù hợp cho tương lai.

\section{CƠ SỞ LÝ LUẬN}

Công việc theo-thủ-tục (routine task) (Daron Acemoglu, David Autor, 2011) được hiểu là công việc thường xuyên có tính chất lặp đi, lặp lại, hầu như không thay đổi, có thể được xác định bởi các bước qui trình cố định sẵn, không mang tính linh động, sáng tạo. Một số ví dụ cho công việc theo-thủ-tục là thư ký đánh máy, kế toán, nhân viên văn thư hay giao dịch viên tại quầy ngân hàng.

Công việc phi-thủ-tục (non-routine task) (Daron Acemoglu, David Autor, 2011) là công việc không theo qui tắc, qui trình cố định hoặc được thực hiện lần đầu. Do không thường lặp lại, công việc phi-thủ-tục thường không quen thuộc, có thể gặp khó khăn nhất định khi mới thực hiện công việc, vì vậy thường đòi hỏi kỹ năng hay nhận thức ở bậc cao hơn. Một số ví dụ cho công việc này ở người có trình độ cao đẳng, đại học trở lên như là bác sĩ, luật sư, chuyên viên quan hệ công chúng.

Nhiều nghiên cứu trên thế giới, chẳng hạn như các nghiên cứu của Daron Acemoglu, David Autor (2011), Maarten Goos (2013), Gregory, Salomons và Zierahn (2016), Wojciech Hardy, Piotr Lewandowski, 
Albert Park (2018) cho thấy tự động hóa có thể làm lượng việc làm ròng tăng nhưng làm giảm việc làm theo-thủ-tục. Điều này có thể được lý giải do các công việc được áp dụng tự động hóa đại trà trước hết là các công việc theo thủ tục cố định, đặc biệt là các công việc có khối lượng thực hiện lớn, kể cả ở các công việc không đơn thuần dùng cơ bắp, mà yêu cầu khả năng nhận thức không quá phức tạp. Bên cạnh đó, tự động hóa sẽ xảy ra ngày càng nhiều hơn để thay thế con người trong các việc (works) có thủ tục mất nhiều thời gian, hoặc nguy hiểm cho con người. Tự động hóa với các robot tự học, có trí tuệ nhân tạo cấp độ cao cũng sẽ diễn ra ở các công việc phi-thủ-tục, nhưng sẽ cần có nhiều thời gian hơn để robot phát triền đến các mức độ nhận thức phức tạp gần như con người.

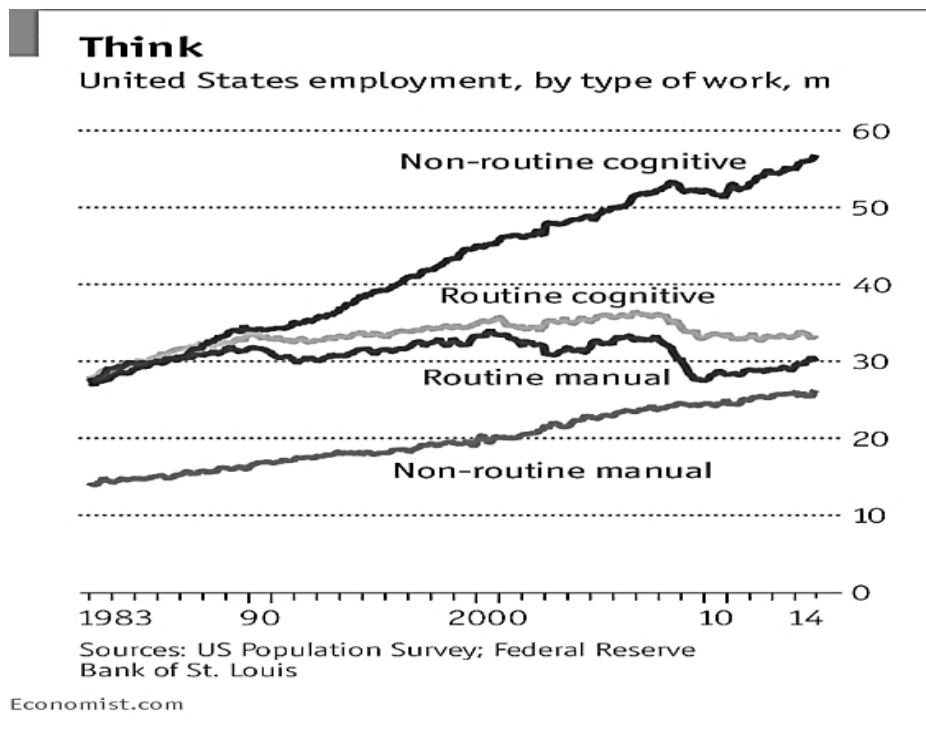

(Nguồn: Economist.com)

Hình 1. Đồ thị tăng truởng việc làm, phân theo các loại công việc theo-thủ-tuc và phi-thủ-tục

Như vậy, để tránh nguy cơ bị thay thế bởi robot hoặc bị đẩy vào các công việc quá giản đơn với thu nhập rất thấp hoặc công việc chân tay đòi hỏi năng khiếu phức tạp nhưng có ít cơ hội việc làm, sẽ cần có sự dịch chuyển khỏi các công việc theo-thủ-tục, sang công việc phi-thủ-tục với năng lực nhận thức cao, có tính linh động sáng tạo.

Để đánh giá hiện trạng, định hướng đào tạo lao động cho phù hợp với Công nghiệp 4.0, nghiên cứu này tìm hiểu tình hình cơ cấu lao động phân nhóm theo công việc theo-thủ-tục hay phi-thủ-tục. Từ đó xác định các thay đổi cần thiết trong chương trình đào tạo để tăng cường các nhóm lao động có năng lực thực hiện tốt các công việc phi thủ tục, sáng tạo.

Để bảo đảm tính tin cậy, phổ biến, nghiên cứu ở đây tiến hành phân loại việc làm của sinh viên sau tốt nghiệp vào các nhóm công việc theo-thủ-tục và phi-thủ-tục dựa trên tiêu chuẩn của Bộ tiêu chuẩn phân loại nghề nghiệp quốc tế ISCO-08 (International Standard Classification Of Occupations ISCO-08). Tiêu chuẩn này được lập ra bởi Tổ chức Lao động Quốc tế (tên tắt ILO) và được cập nhật vào năm 2012. ISCO-08 được phát triển nhằm tạo thuận tiện cho sự so sánh quốc tế giữa các kết quả thống kê ngành nghề lao động của các tổ chức khác nhau cùng tuân thủ chuẩn này. ISCO-08 được áp dụng cho cả các quốc gia đang phát triển hay tái phân loại ngành nghề và được cộng đồng quốc tế, trong đó có Tổng cục thống kê Việt Nam (tên tắt là TCTK, tên tắt tiếng Anh là GSO) sử dụng vào thống kê lao động việc làm của quốc gia.

\section{PHƯƠNG PHÁP NGHIÊN CÚU}

Để đạt được mục tiêu nghiên cứu, bài viết này sử dụng phối hợp cả hai phương pháp định lượng và định tính. Trước tiên, phương pháp định lượng được áp dụng với mẫu được chọn từ tổng thể sinh viên đã tốt nghiệp của IUH. Mẫu được lấy theo phương pháp phi ngẫu nhiên thuận tiện và sau khi đã loại các dữ liệu thiếu sót, thông tin thiếu độ tin cậy, quy mô mẫu có được gồm 320 quan sát. Bảng khảo sát (xem chi tiết tại phần Phu luc ) gồm 12 câu hỏi chính được thiết kế để thu thập thông tin thực trạng việc làm và tính 
chất công việc của sinh viên sau tốt nghiệp từ IUH - đại diện cho cả hai khối là khối ngành Kinh tế - Xã hội (180 quan sát) và khối ngành Kỹ thuật - Công nghệ (140 quan sát). Kỹ thuật dự báo theo dãy số thời gian với phương pháp dự báo theo đường xu hướng (Method of trend forecasting) được sử dụng để dự báo và xác định xu hướng dài hạn về cơ cấu việc làm của lao động có trình độ và công việc tương đương với sinh viên sau tốt nghiệp IUH.

Kế tiếp, phương pháp định tính được dùng chủ yếu để thu thập, phân tích, đánh giá các nhận định của các chuyên gia trong các lĩnh vực liên quan nhằm nêu kết luận, giải pháp thích hợp cho việc định hướng các thay đổi cần thiết trong tương lai để thích ứng với xã hội Công nghiệp 4.0. Nội dung phỏng vấn chuyên gia chuyên sâu vào lĩnh vực đào tạo nhân lực thực tế tại IUH, làm rõ hơn về cơ cấu đào tạo hiện tại của nhà trường và cơ cấu phù hợp cho việc làm trong Công nghiệp 4.0. Phân tích định tính ở đây còn có mục đích làm rõ các nhận định của các chuyên gia quốc tế có uy tín, kinh nghiệm trong nghiên cứu các lĩnh vực liên quan đến Công nghiệp 4.0.

\section{NỘI DUNG PHÂN TÍCH}

\subsection{Khung phân loại tính chất việc làm theo-thủ-tục hay phi-thủ-tục}

Nghiên cứu này sử dụng cách phân loại việc làm của sinh viên sau tốt nghiệp trên cơ sở nghề nghiệp và cấp độ kỹ năng được yêu cầu trong thực hiện công việc thường xuyên. Khai thác ưu điểm chi tiết, rõ ràng của phân loại việc làm theo tiêu chuẩn ISCO-08, kết quả khảo sát công việc cựu sinh viên được dùng để phân chia mỗi cá nhân vào nhóm tương ứng theo ISCO-08.

Trong ISCO-08, ngoài phân nhóm theo nghề nghiệp (occupation), mỗi cá nhân còn phân loại được theo cấp độ kỹ năng yêu cầu của công việc của họ vào bốn nhóm 1 đến 4 . Trong nội dung ISCO-08, mỗi nhóm chính, phụ hay mỗi cấp độ kỹ năng cũng được giải thích khá rõ các tính chất công việc tương ứng, khá thuận lợi để gán vào các bậc phân loại công việc là theo-thủ-tục hay phi-thủ-tục.

Nhằm đáp ứng cả hai mục tiêu là dự báo cơ cấu việc làm của sinh viên sau tốt nghiệp IUH và định hướng cơ cấu đào tạo phù hợp với thời kỳ Công nghiệp 4.0 đang diễn ra trên thế giới và ở Việt Nam, nghiên cứu này áp dụng phối hợp hai tiêu chuẩn phân loại việc làm theo tiêu chuẩn của TCTK và theo tiêu chuẩn quốc tế ISCO-08.

Việc ráp nối hai bộ tiêu chuẩn này được dựa trên danh mục nghề nghiệp trong bảng "Lao động từ 15 tuổi trở lên đang làm việc hàng năm phân theo nghề nghiệp" của TCTK (bảng 2) cùng danh mục các nghề nghiệp theo các Nhóm chính (Major group) trong ISCO-08.

Bảng 1. Các nhóm chính và các cấp độ kỹ năng tương ứng theo ISCO-08

\begin{tabular}{|l|c|}
\hline Các nhóm chính ISCO-08 & Cấp độ kỹ năng \\
\hline 1. Nhà quản lý & $3+4$ \\
2. Chuyên gia & 4 \\
3. Kỹ thuật viên và phụ tá chuyên gia & 3 \\
4. Nhân viên văn thư & 2 \\
5. Nhân viên bán hàng và dịch vụ & \\
6. Công nhân nông lâm nghiệp lành nghề & \\
7. Nghề thủ công và các ngành nghề liên quan & \\
8. Vận hành nhà máy và máy móc, và lắp ráp & \\
9. Nghề phổ thông đơn giản & 1 \\
10. Lực lượng vũ trang & $1+2+4$ \\
\hline
\end{tabular}

Nguồn: Dịch tì̀ ILO (2012), International Standard Classification Of Occupations ISCO-08, vol.1,p.14 
Bảng 2. Danh mục phân nhóm theo nghề nghiệp lao động tù 15 tuổi trở lên đang làm việc tại Việt Nam

\begin{tabular}{|c|l|}
\hline Nhóm & \\
\hline 1 & Nhà lãnh đạo \\
\hline 2 & Chuyên môn kỹ thuật bậc cao \\
\hline 3 & Chuyên môn kỹ thuật bậc trung \\
\hline 4 & Nhân viên \\
\hline 5 & Dịch vụ cá nhập, bảo vệ và bán hàng \\
\hline 6 & Nghề trong nông, lâm, ngư nghiệp \\
\hline 7 & Thợ thủ công và các thợ khác có liên quan \\
\hline 8 & Thợ lắp ráp và vận hành máy móc thiết bị \\
\hline 9 & Nghề giản đơn \\
\hline 10 & Không phân loại \\
\hline
\end{tabular}

Ráp nối các nhóm theo ISCO-08 sang các nhóm việc làm theo TCTK giúp sử dụng các kết quả thống kê của TCTK vào phân tích xu hướng thực tại tiếp diễn trong cơ cấu nhân lực lao động Việt Nam, từ đó dự báo cơ cấu việc làm của sinh viên sau tốt nghiệp IUH theo xu hướng chung của quốc gia.

Phân loại việc làm của sinh viên sau tốt nghiệp IUH đã được khảo sát dựa trên ISCO-08 kết hợp với phân loại của TCTK giúp đối chiếu, so sánh, xem xét sự phù hợp của công việc thực tế của họ với các công việc được các chuyên gia quốc tế công nhận về khả năng phát triển trong Công nghiệp 4.0.

\subsection{Thực trạng việc làm của sinh viên sau tốt nghiệp IUH phân theo loại việc làm theo-thủ-tục và phi-thủ-tục}

Đối tượng và phạm vi khảo sát thực tế là công việc của các sinh viên đã tốt nghiệp từ IUH. Khảo sát đã thu thập được mẫu dữ liệu hợp lệ gồm 320 quan sát, trong đó có 180 cựu sinh viên đại diện khối ngành Kinh tế- Xã hội và 140 đại diện khối ngành Kỹ thuật- Công nghệ.

Kết quả khảo sát công việc của cựu sinh viên được đánh giá, nhận xét, từ đó xếp loại việc làm của họ vào phân nhóm theo-thủ-tục hay phi-thủ-tục tương ứng. Các thông tin được sử dụng để phân loại công việc cá nhân thực tế gồm nghề nghiệp, công việc chính đang thực hiện, chức vụ, mức độ thành thạo về tin học, nhận xét của cá nhân được khảo sát về tính theo thủ tục quy trình sẵn có của công việc, mức độ thực tế sử dụng phần mềm lập trình sẵn cho công việc. Ngoài ra, các thông tin khác cũng được tham khảo để xếp loại công việc chính xác hơn như chuyên ngành tốt nghiệp, bộ phận làm việc, ngành nghề của công ty, tổ chức đang làm việc, quy mô của tổ chức. Chẳng hạn các công việc ở địa vị lãnh đạo, các công việc không có quy trình cố định, nhất là ở các tổ chức qui mô lớn, kèm với tính chất công việc là không thể tiến hành theo kiểu áp cứng theo phần mềm lập trình sẵn được coi là công việc mang tính phi-thủ-tục.

Kểt quả trong tổng số 320 cựu sinh viên được khảo sát có đến 185 người hiện có công việc mang tính theo-thủ-tục, chiếm 57,83\% mẫu quan sát, số còn lại 135 người có công việc mang tính phi-thủ-tục, chiếm $42,17 \%$ mẫu quan sát.

Xét về chuyên ngành tốt nghiệp, có 95 người trong 180 người chiếm $52,78 \%$ cựu sinh viên đại diện khối ngành Kinh tế - Xã hội có công việc thiên về loại theo-thủ-tục, trong khi đó 90 người trong 140 người chiếm đến 64,29\% cựu sinh viên đại diện khối ngành Kỹ thuật - Công nghệ có công việc chủ yếu mang tính theo-thủ-tục. Sự khác biệt giữa hai khối ngành có thể được giải thích bởi tính mở cao hơn ở khối ngành Kinh tế- Xã hội so với tính gắn kết với các qui trình thủ tục kỹ thuật sẵn có của công việc ở các ngành Kỹ thuật- Công nghệ. 


\subsection{Xu hướng thực tại trong cơ cấu nhân lực lao động Việt Nam có công việc với trình độ tương đương đại học, cao đẳng, phân theo loại việc làm theo-thủ-tục và phi-thủ-tục}

Căn cứ trên yêu cầu công việc chủ yếu liên quan đến trình độ sinh viên sau tốt nghiệp đại học và cao đẳng Việt Nam, và dựa vào ý nghĩa các tên gọi nghề nghiệp theo TCTK, đối chiếu với các phân nhóm nghề nghiệp của ISCO-08 và các cấp độ kỹ năng tương ứng, nghiên cứu này phân các nghề nghiệp trong danh mục ở bảng 2 thành hai nhóm là công việc phi-thủ-tục bao gồm các nhóm từ 1 đến 3 và công việc theo thủ tục gồm các nhóm 4 và 5 .

Kết quả phân tích định lượng (biểu đồ 1 ) cho thấy thực tế nhu cầu của thị trường lao động Việt Nam đối với các công việc chủ yếu có tính phi-thủ-tục đều đang tăng, trong đó ở nhóm 2 lao động có tay nghề cao đang có xu hướng tăng cao nhanh khá rõ so với các nhóm khác. Nhóm 1 nhà lãnh đạo và nhóm 3 lao động có tay nghề bậc trung tuy cũng có xu hướng tăng nhưng so với nhóm 2 trong cùng kỳ thì mức tăng chậm hơn rất nhiều (hệ số độ dốc đường hồi quy của nhóm 1 là 2.42 từ quý 1 năm 2012 đến quý 2 năm 2018, nhóm 3 là 6.47 từ quý 2 năm 2013 đến quý 2 năm 2018 trong khi độ dốc đường hồi quy của nhóm 2 cùng kỳ với nhóm 3 là 49,57)

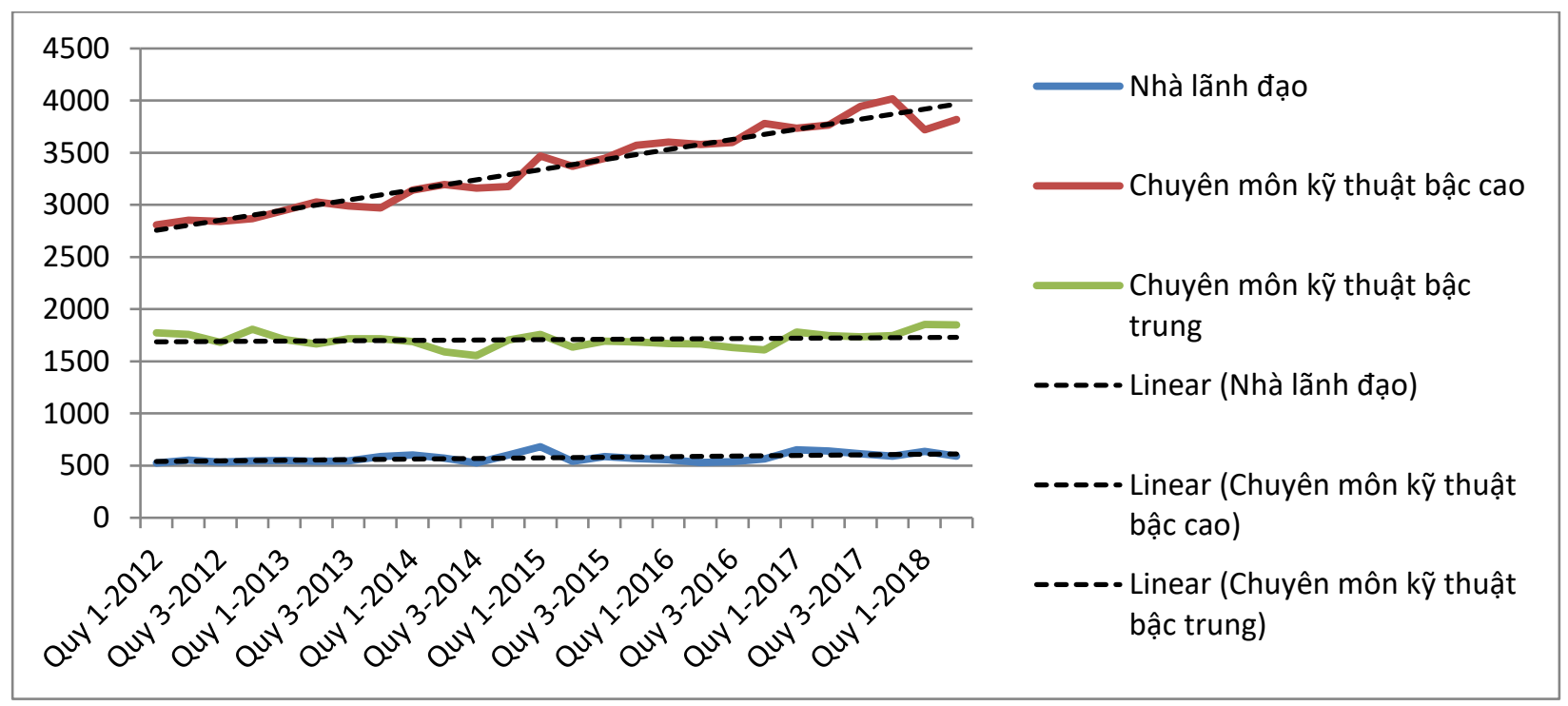

(Đơn vị: ngàn người)

Nguồn số liệu: Tổng cục thống kê Việt Nam

Biểu đồ 1. Luợng lao động Việt Nam theo nghề nghiệp chủ yếu phi-thủ-tuc

Các đường xu hướng (Linear) được kiểm chứng đều có ý nghĩa thống kê với độ tin cậy $99 \%$. 


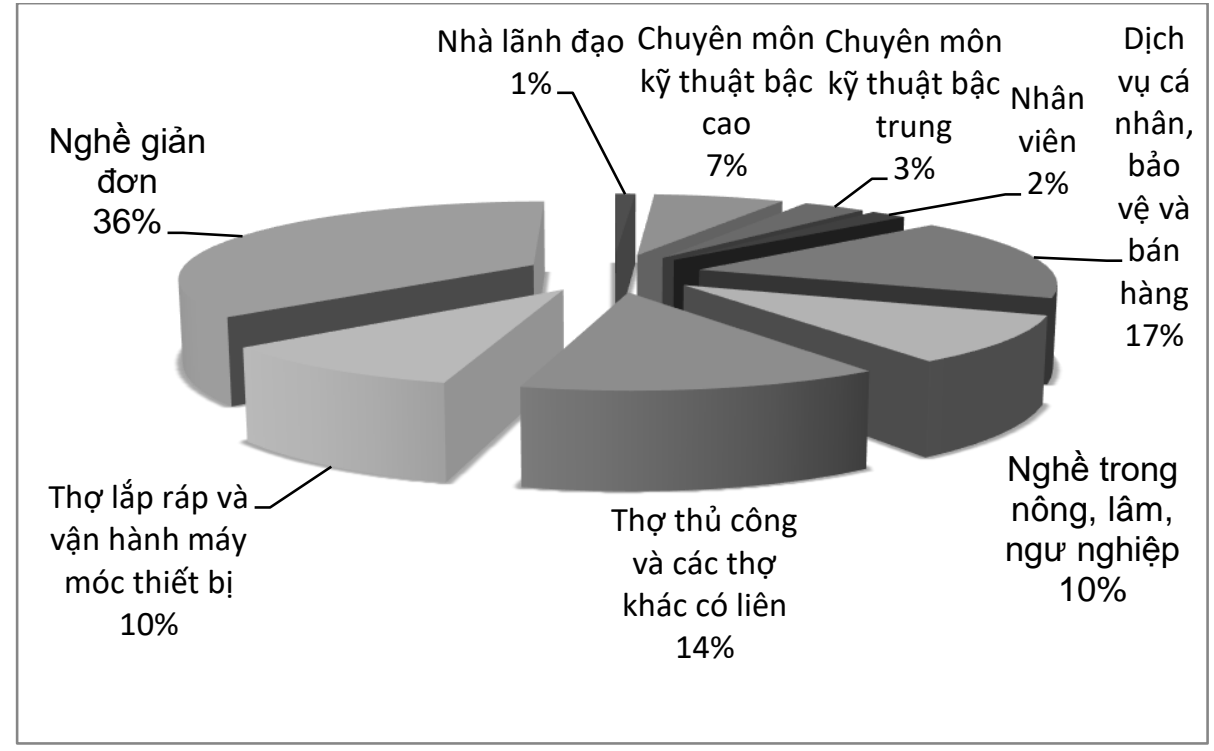

Nguồn số liệu: Tổng cuc thống kê Việt Nam

Biểu đồ 2. Tỉ lệ thành phần lao động Việt Nam theo nghề nghiệp

Thêm vào đó, trong nghiên cứu về quá trình chuyển đổi ở Châu Á (Asian in Transfomation) của ILO, Jae-Hee Chang and Phu Huynh (2016) chỉ ra rằng, cơ cấu lao động của lực lượng lao động Việt Nam vẫn còn nghiêng nhiều về phía kỹ năng thấp, khó thực hiện các công việc phức tạp thường không có bài bản thủ tục sẵn. Tỉ lệ lao động Việt Nam có kỹ năng thấp chiếm hơn $40 \%$ lao động, cao nhất trong năm nước vùng Đông Nam Á gồm Campuchia, Indonesia, Philippin, Thái Lan, Việt Nam. Ở Thái Lan tỉ lệ này chưa đến $10 \%$, Philippin khoảng $33 \%$ và ở Campuchia chỉ khoảng $18 \%$ (hình 4 ).

Nghiên cứu của Jae-Hee Chang and Phu Huynh (2016) cũng đánh giá mức độ rủi ro bị thay thế bởi tự động hóa dựa trên ngành nghề phổ biến tại mỗi nước và cả vùng năm quốc gia ASEAN (ASEAN-5) (hình $3)$, kết quả tỉ lệ lao động gặp rủi ro cao tính trung bình trên cả vùng là $56 \%$, thì tỉ lệ đó của riêng Việt Nam là $70 \%$, cao nhất so với bốn nước còn lại, nước có tỉ lệ cao thứ hai là Campuchia chỉ ở mức $57 \%$.

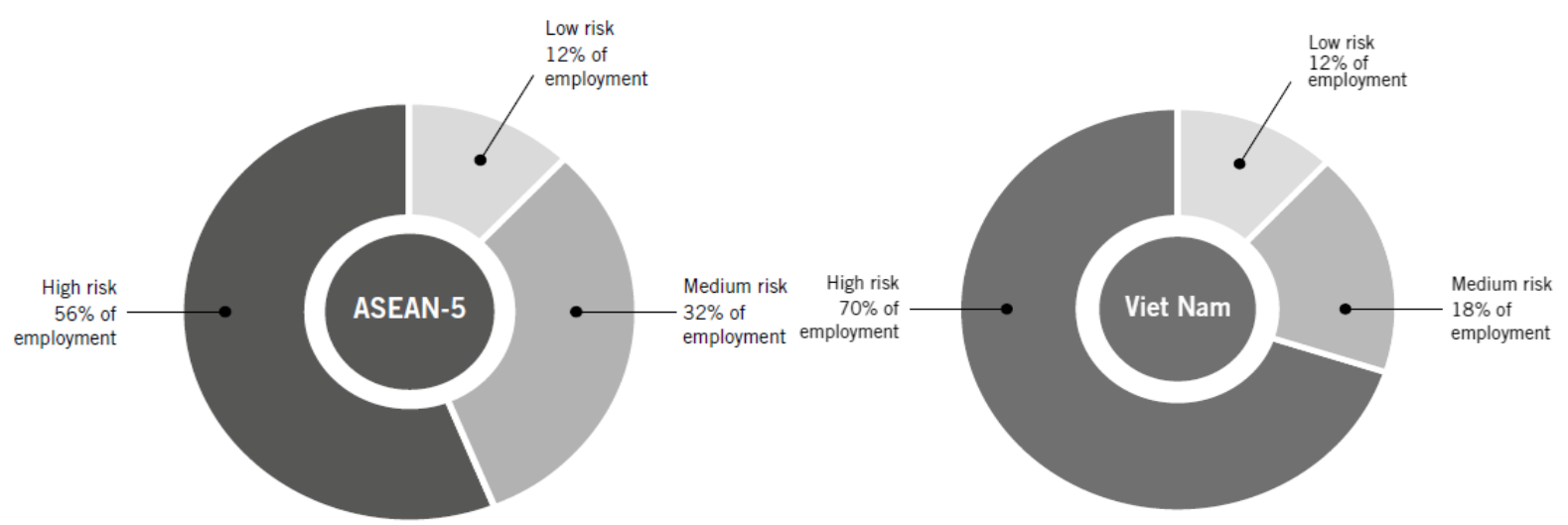

Nguồn: Jae-Hee Chang and Phu Huynh (2016).

Hình 2. Tỉ lệ lương lao động gặp rủi ro mất việc làm do tụ động hóa 
Skill level

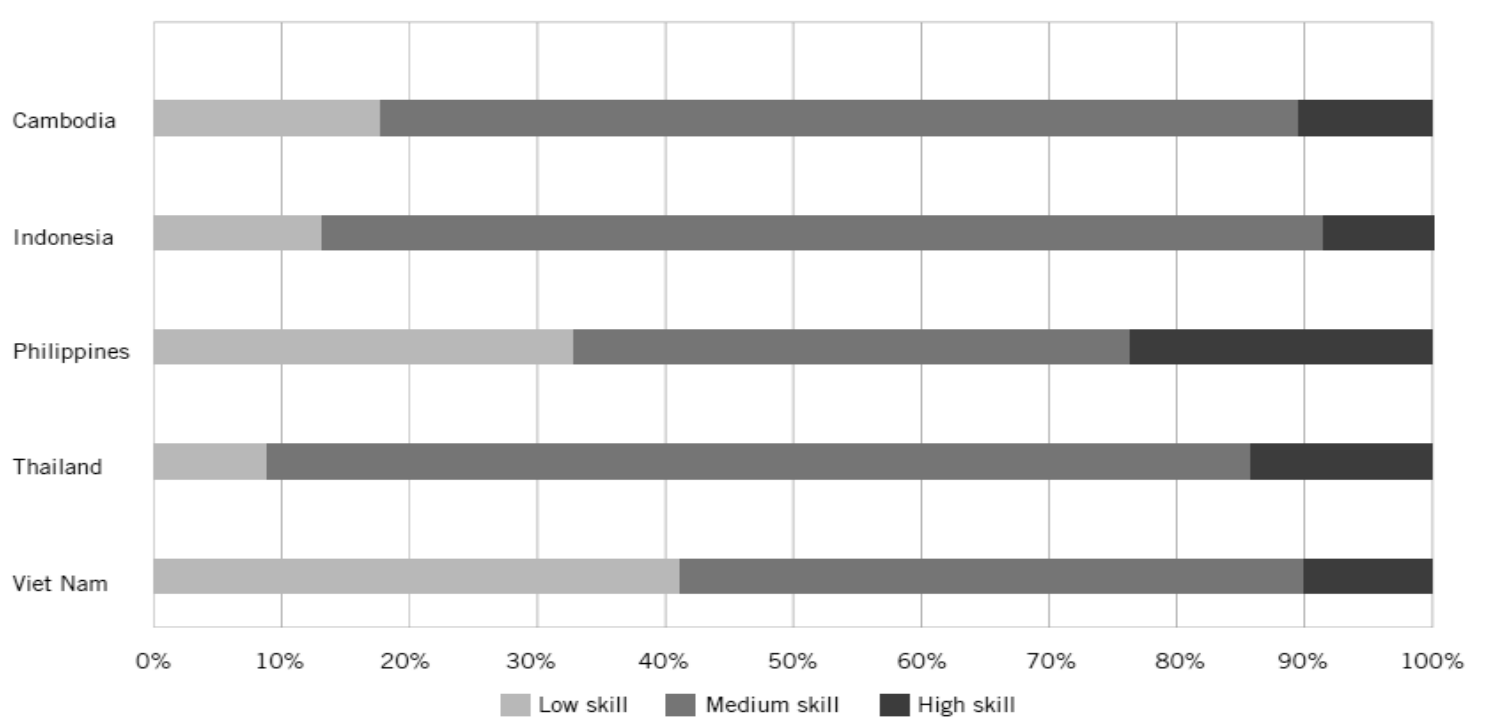

Nguồn: Jae-Hee Chang and Phu Huynh (2016).

Hình 3. Tỉ lệ lực lượng lao động tính trên mưc độ kỹ năng.

Như vậy, xét ở cấp độ quốc gia, có thể thấy khi đổi mới sức cạnh tranh Việt Nam sẽ cần nâng cấp một lượng lớn lao động để chuyển sang khu vực có kỹ năng cao hơn với công việc phi-thủ-tục. Điều này rõ ràng sẽ dẫn đến xu thế gia tăng mạnh lượng nhu cầu cho công việc phi-thủ-tục.

3.4. Phân tích ý kiến chuyên gia để xác định hướng đào tạo hiện tại của nhà trường, dẫn đến làm rõ hơn cơ cấu năng lực việc làm trong tương lai theo chương trình đào tạo hiện tại ở nhà trường phân chia theo loại việc làm theo-thủ-tục hay phi-thủ-tục

Theo ý kiến khảo sát các chuyên gia có nhiều năm kinh nghiệm giảng dạy và quản lý tại IUH, thì nhà trường đã sớm có chủ trương cải tiến chương trình đào tạo theo hướng đáp ứng nhu cầu lao động trong thời kỳ Công nghiệp 4.0, định hướng đổi mới, sáng tạo. Tuy nhiên, xét về nội dung giảng dạy thực tế trong các giáo trình, tài liệu giảng của phần lớn giảng viên vẫn còn nặng tính hướng dẫn sinh viên thực hiện công việc theo-thủ-tục sẳn có. Để có thể thay đổi thực tế này cần có sự xác nhận rõ ràng về sự cần thiết trong việc xây dựng cách dạy và học theo hướng tạo cho sinh viên năng lực thực hiện các công việc phi thủ tục, từ đó có thể cải tiến chương trình cho phù hợp.

\subsection{Dự báo xu hướng năng lực đáp ứng công việc của sinh viên sau tốt nghiệp từ IUH, phân chia theo loại công việc theo-thủ-tục hay phi-thủ-tục}

Sử dụng kết quả khảo sát sinh viên IUH sau tốt nghiệp, giả định kỹ năng tối thiểu của họ gia tăng tương đồng với lao động có trình độ tương đương trên cả nước, kết hợp với đường xu hướng cơ cấu việc làm của lao động Việt Nam cho thấy tốc độ gia tăng của việc làm phi-thủ-tục đạt $4 \% /$ năm so với tốc độ tăng tổng lượng việc làm là $1 \% /$ năm. Kết quả tính toán dự báo tỉ lệ sinh viên sau tốt nghiệp IUH có loại công việc theo-thủ-tục và phi-thủ-tục như Bảng 3 .

Thực tế tự động hóa bằng robot, trí tuệ nhân tạo và nhiều công nghệ mới khác đang phát triển với tốc độ khó lường, không thể tiên đoán (WEF White Paper, 2018), đem đến các thay đổi sâu rộng, không tuyến tính theo quá khứ. Từ đó nhu cầu và khả năng đáp ứng của lao động thực tế có khả năng thay đổi khó lường. Tuy nhiên, để có cái nhìn tổng quan trong điều kiện không thể có đầy đủ mọi số liệu thực tế, nghiên cứu này sử dụng tính tuyến tính trong dự báo ở bảng 3 . 
CỦA SINH VIÊN ĐẠI HỌC CÔNG NGHIỆP TP.HCM SAU KHI TỐT NGHIỆP

Bảng 3. Dụ báo tỉ lệ co cấu tỉ lệ sinh viên sau tốt nghiệp IUH phân chia công việc theo-thủ-tục và phi-thủ-tục

\begin{tabular}{|l|c|c|}
\hline \multirow{2}{*}{ Năm } & \multicolumn{2}{|c|}{ Dự báo tỉ lệ (\%) sinh viên sau tốt nghiệp có loại công việc } \\
\cline { 2 - 3 } & Theo-thủ-tục & Phi-thủ-tục \\
\hline 2019 & $58 \%$ & $42 \%$ \\
\hline 2020 & $55 \%$ & $45 \%$ \\
\hline 2021 & $52 \%$ & $48 \%$ \\
\hline 2022 & $49 \%$ & $51 \%$ \\
\hline 2023 & $46 \%$ & $54 \%$ \\
\hline
\end{tabular}

Nguồn: Kết quả dụ báo của tác giả

3.6. Phân tích ý kiến chuyên gia quốc tế để xác định hướng cơ cấu công việc phù hợp trong Công nghiệp 4.0, phân chia theo loại công việc theo-thủ-tục hay phi-thủ-tục

Bảng 4. Ví dụ phân loại nghề nghiệp theo các công việc và kỹ năng

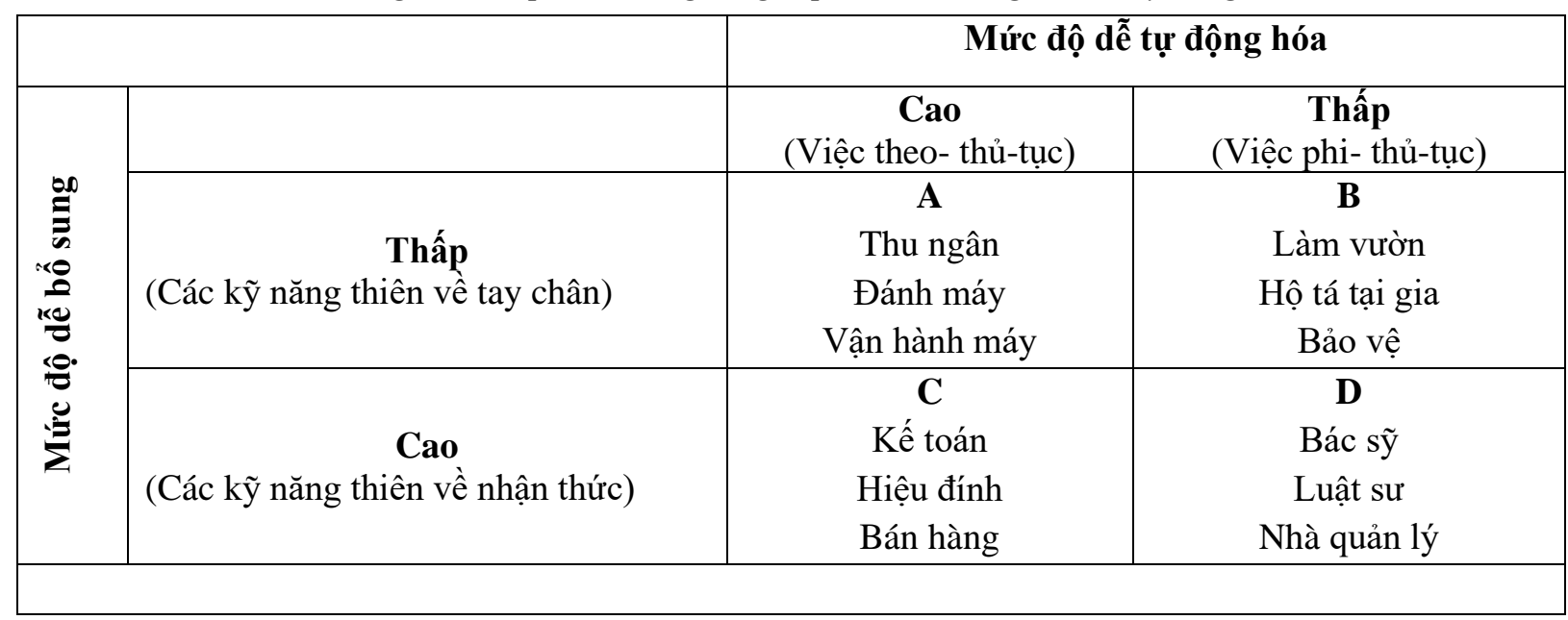

Nguồn: Ngân hàng thế giới (WB) dẫn tù̀ ý của tác giả là D. Acemoglu và D. Autor.

Dẫn ý từ nghiên cứu vào năm 2011 của hai nhà kinh tế học Daron Acemoglu, Giáo sư tại học viện MIT, và David Autor, giáo sư trường Harvard (Mỹ) về quan hệ giữa nhu cầu của thị trường lao động với sự phát triển công nghệ, Jae-Hee Chang \& Phu Huynh (2016) đã đưa ra ví dụ phân biệt khả năng bị thay thế do tự động hóa của bốn nhóm công việc (bảng 4), trong đó hai nhóm công việc theo-thủ-tục gồm (A) công việc thiên về chân tay và $(\mathrm{C})$ thiên về nhận thức đều thuộc loại dễ dàng tự động hóa, hai nhóm còn lại có công việc loại phi-thủ-tục là (B) thiên về chân tay và (D) thiên về nhận thức đều được coi là khó tự động hóa. Chẳng hạn các công việc thuộc nhóm $(\mathrm{A})$ như thu ngân, đánh máy chữ, điều khiển máy móc và nhóm (C) như kể toán ghi chép nghiệp vụ, người hiệu đính văn bản, nhân viên bán hàng thuộc loại theo-thủ-tục; nhóm $(B)$ như người làm vườn, hộ tá tại gia, nhân viên an ninh và nhóm $(\mathrm{D})$ như bác sỹ, luật sư, nhà quản lý thì có công việc phi-thủ-tục. Nếu chỉ xét các nhóm có trình độ tương đương đại học, cao đẳng và trên đại học, có thể nhận xét chỉ có công việc nhóm (D) thuộc loại phi-thủ tục. Jae-Hee Chang \& Phu Huynh (2016) cũng chỉ ra rằng công việc của nhóm $(\mathrm{D})$ ngoài khó tự động hóa còn khó rơi vào nhóm thu nhập thấp.

L. Rafael Reif, Chủ tịch Viện MIT, trong tham luận trình bày tại Diễn đàn Kinh tế Thế giới WEF tại Davos vào năm 2018, đã liệt kê xác suất bị tự động hóa của một số việc làm phổ biến (hình 4), trong đó các việc thường theo-thủ-tục thì gặp rủi ro cao nhất như nhân viên theo dõi nợ $(98 \%)$, kế đến là tiếp tân, phụ tá luật sư, nhân viên bán lẻ, tài xế, bảo vệ an ninh, đầu bếp thức ăn nhanh, pha chế thức uống (77\%), đến cố vấn tài chính cá nhân, và ngay cả lập trình viên máy tính cũng có xác suất bị thay bởi tự động hóa lên đến $48 \%$. Ở phía ngược lại, các công việc khó tự động hóa bao gồm những việc mang tính sáng tạo, phi-thủ-tục như giáo viên mầm non, chuyên gia phẩu thuật và trị liệu vật lý, luật sư, ca sỹ và nhạc sỹ. 


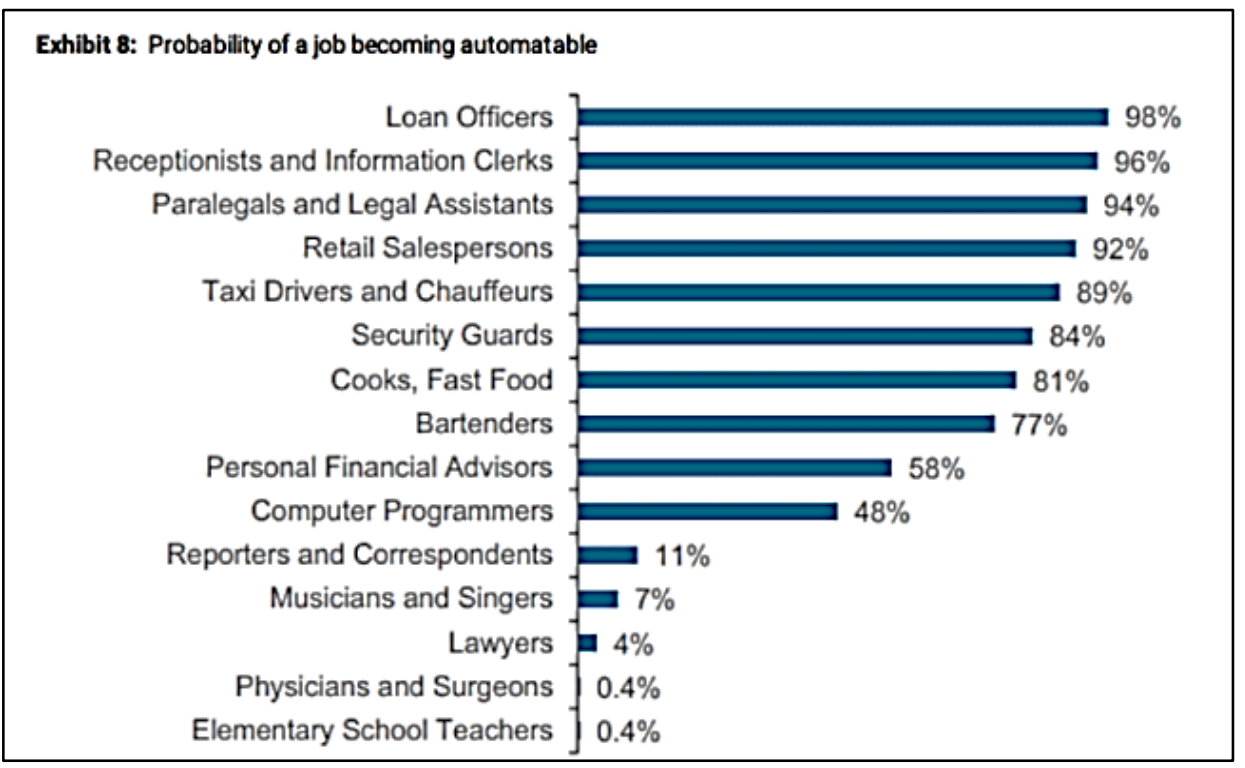

Nguồn: Đại học Oxford, C.B.Frey và M.Osborne, Morgan Stanley Research.

Hình 4. Xác suất của một số loại việc làm mất đi do bị tự động hóa.

\section{TỔNG HợP KẾT QUẢ NGHIÊN CỨU}

Kết quả phân tích các nội dung nghiên cứu ở mục 4 đã cho thấy:

- Việc phân loại công việc theo Bộ tiêu chuẩn ISCO-08 của ILO tạo cơ sở dễ phân theo tính theo-thủtục hay phi-thủ-tục, từ đó thuận tiện phân định được các loại công việc nào gặp rủi ro bị thay thể do tự động hóa. Điều này sẽ tạo điều kiện cho các tổ chức đào tạo, cung ứng lao động có thể xác định được các ngành nghề cụ thể cần đào tạo để bảo đảm việc làm cho nhân lực đầu ra.

- Thực tế khảo sát định lượng cho thấy các công việc thực hiện bởi sinh viên sau tốt nghiệp IUH thì phần lớn hơn vẫn thuộc loại theo-thủ-tục. Tuy có sự tăng trưởng các công việc phi-thủ-tục trong xu hướng chung của thị trường lao động Việt Nam, nhưng so với các quốc gia khác kể cả ở Đông Nam Á, lao động Việt Nam nói chung, sinh viên tốt nghiệp đại học Việt Nam nói riêng đang nằm ở vị thế cạnh tranh kém do phần lớn thiếu kỹ năng ở bậc cao, nhất là khả năng thực hiện các công việc mang tính phi-thủ-tục, sáng tạo.

- Kết quả trả lời bảng câu hỏi khảo sát còn cho thấy một thực trạng đáng quan tâm là quan điểm định hướng của không ít cựu sinh viên đang giữ địa vị chủ chốt của nhiều tổ chức ở khối Khoa học - Công nghệ còn thể hiện sự đề cao tính theo-thủ-tục trong công việc, biểu hiện ý muốn phát triển công việc cá nhân và tổ chức theo hướng quy trình hóa theo thủ tục. Trong khi phần lớn mọi câu trả lời khác đều khá hợp lý với vị trí việc làm và chức vụ của mình, thì phần trả lời về tính chất công việc hiện tại, $77 \%$ nhà quản lý, lãnh đạo được khảo sát ở khối Khoa học - Công nghệ cho rằng công việc cá nhân chủ yếu theo quy trình sẵn có, không mang tính linh động. Câu trả lời này mâu thuẫn với tính chất công việc của nhà quản trị - là nghề nghiệp đòi hỏi rất nhiều tính linh hoạt, sáng tạo và đặc biệt không theo quy trình cứng nhắc - và rõ ràng quan điểm này không phù hợp, thậm chí tạo sự rủi ro cho chiến lược phát triển tổ chức trong thời đại Công nghiệp 4.0. Để thay đổi lối tư duy kỹ thuật này, sẽ cần đến một định hướng trong đào tạo tại nhà trường, đồng thời cần tạo điều kiện cho sinh viên khối Kỹ thuật - Công nghệ nói riêng và mọi khối ngành nói chung, tiếp cận với thực tế công việc trong môi trường kinh tế - xã hội của Công nghiệp 4.0.

- Trong khi đó, các chuyên gia quốc tế đều nhận định các công việc của người có trình độ sau tốt nghiệp đại học, cao đẳng trong thời kỳ Công nghiệp 4.0 sẽ chủ yếu thuộc loại phi- thủ-tục. Công nghiệp 4.0 đang phát triển nhanh chóng, tự động hóa sẽ gia tăng nhanh với tốc độ khó lường, sẽ ngày càng tăng tốc lấy đi nhiều công việc theo-thủ-tục.

Như vậy có thể kết luận rằng để bảo đảm việc làm cho sinh viên sau tốt nghiệp trong thời kỳ Công nghiệp 4.0, nhà trường cần định hướng rõ ràng cho việc tăng cường đào tạo ngành nghề, công việc có tính 
phi-thủ-tục, chuẩn bị sẵn sàng cho một thị trường lao động có nhiều ngành nghề mới, chưa có bài bản thủ tục sẵn có.

\section{5 ĐẾ XUẤT GIẢI PHÁP}

Để giải quyết cụ thể vấn đề định hướng đào tạo năng lực thực hiện công việc phi thủ tục, sáng tạo, đáp ứng đúng nhu cầu lao động trong Công nghiệp 4.0, một số giải pháp đề xuất cho các đơn vị đào tạo đại học nói chung và IUH nói riêng như sau:

- Thứ nhất, áp dụng Bộ tiêu chuẩn ISCO-08 của Tổ chức Lao động Quốc tế ILO để xác định các ngành nghề, công việc mang tính phi-thủ-tục ít rủi ro bị thay thế trong thời kỳ tự động hóa 4.0 , từ đó xây dựng chương trình đào tạo với các chuẩn đầu ra đảm bảo sinh viên sau tốt nghiệp thực hiện được các công việc này. Đồng thời đồi mới nội dung giảng dạy cả trong các môn kinh tế xã hội hay kỹ thuật sao cho phù hợp các công việc phi thủ tục, sáng tạo. Tăng cường dạy và học các môn học giúp phát triển năng lực đổi mới, sáng tạo của sinh viên, chẳng hạn như các môn liên quan kỹ năng lãnh đạo, năng lực khởi nghiệp. Nâng cao mức độ yêu cầu về năng lực công nghệ thông tin, ngoại ngữ cả đối với các ngành kỹ thuật và xã hội để bảo đảm kỹ năng ở mức 3 hoặc 4 trong Bộ tiêu chuẩn ISCO-08 của ILO.

- Thứ hai, sớm xây dựng ý thức, kiến thức và trải nghiệm về môi trường công việc trong Công nghiệp 4.0. Trong đó việc xây dựng một hệ thống thực nghiệm cho sinh viên tiếp cận với Công nghiệp 4.0 là hết sức cần thiết, cấp bách. Theo thông tin mới nhất từ chuyên gia nội bộ trong nhà trường cung cấp, IUH hiện nay đang có cơ hội nhận được tài trợ từ Tập đoàn quốc tế Siemens, một trong các nhà cung cấp hàng đầu thế giới cho giải pháp tổng thể tự động hóa toàn bộ chuỗi giá trị trên nền công nghệ của Công nghiệp 4.0. Đây thực sự là một cơ hội quý, hợp thời điểm giúp nhà trường tăng cường năng lực hiểu biết, trải nghiệm cho giảng viên và sinh viên về Công nghiệp 4.0.

- Thứ ba, bảo đảm hệ thống thông tin liên tục cập nhật, công bố rộng rãi các thay đổi về tình hình công việc mới trên thị trường lao động, tăng cường khuyến khích tinh thần sáng tạo, đổi mới qua việc gia tăng hỗ trợ, cổ động tinh thần doanh nhân trong mọi hoạt động của nhà trường.

- Thứ tư, phát triển đào tạo từ xa, tái đào tạo các ngành nghề mới cho các sinh viên sau tốt nghiệp, chưa có việc làm hay mất việc do chuyên môn đã lỗi thời, hay cả cựu sinh viên từ trường khác.

\section{HẠN CHẾ VÀ HƯỚNG NGHIÊN CÚU TIẾP THEO}

Với các nghiên cứu mở rộng gần đây nhất trên thế giới, có sự phát sinh ngày càng nhiều nhu cầu tách biệt sâu hơn, không chỉ giữa các công việc theo-thủ-tục và công việc phi- thủ-tục, mà còn phân biệt giữa các công việc phi- thủ-tục khác nhau, chẳng hạn giữa các việc có thể đảm trách bởi các robot trí tuệ nhân tạo $(\mathrm{AI})$ với robot tự học (machine learning) nhằm phân chia công việc và phối hợp giữa con người và máy móc để đạt hiệu quả cao nhất. Điều này đòi hỏi cần có sự nghiên cứu sâu hơn trong nghiên cứu các việc (works) cụ thể, không chỉ theo loại công việc (tasks), cũng như cần tiếp cận nhiều thực nghiệm hơn trong môi trường Công nghiệp 4.0, từ đó sẽ dự báo tình trạng việc làm chính xác hơn, nêu giải pháp đầy đủ hơn. Ngoài ra, sự thay đổi nhanh chóng của thế giới xung quanh trong thời đại mới mang đến sự không chắc chắn cho các tiên đoán trước nên việc mở rộng hay thay đổi, cập nhật các nghiên cứu là luôn cần thiết.

\section{LÒ̀I CẢM ƠN}

Chủ nhiệm đề tài, nhóm nghiên cứu trân trọng cám ơn Trường Đại học Công nghiệp Tp.HCM đã cấp kinh phí thực hiện đề tài "Dự báo tác động của Công nghiệp 4.0 đến việc làm của sinh viên Đại học Công nghiệp TP.HCM sau khi tốt nghiệp", mã số "183.KD01", thực hiện năm "2018”.

\section{TÀI LIỆU THAM KHẢO}

[1] Anders Akerman, Ingvil Gaarder, Magne Mogstad (2015), The Skill Complementarity of Broadband Internet, The Quarterly Journal of Economics, 130 (4), 1781-1824

[2] Asian Development Bank (ADB) (2018), Asian Development Outlook 2018: How Technology Affects Jobs, [Online] <https://www.adb.org/sites/default/files/publication/411666/ado2018.pdf>[Truy cập ngày 12.4.2019] 
[3] Barclays (2018), Robots at the gate: Humans and technology at work [Online] <https://www.investmentbank.barclays.com/content/dam/barclaysmicrosites/ibpublic/documents/ourinsights/Robots-at-the-gate/Barclays-Impact-Series-3-Robots_at_the_Gate-3MB.pdf $>$ [Truy cập ngày 07.6.2019]

[4] Bakhshi, Hasan, et al.(2017), The Future of Skills: Employment in 2030, Pearson, Nesta and The Oxford Martin School, [Online] <https://futureskills.pearson.com/research/assets/pdfs/technical-report.pdf>[Truy cập ngày 12.4.2019]

[5] Balliester, Thereza \& Adam Elsheikhi (2018), The Future of Work: A Literature Review, ILO Research Department Working Paper No. 29, International Labour Organization

[6] Berg, Andrew, Edward Buffie \& Luis-Felipe Zanna (2018), Should We Fear the Robot Revolution? (The Correct Answer is Yes), IMF Working Paper No. 18/116, International Monetary Fund

[7] David Autor (2010), The Polarization of Job Opportunities in the U.S. Labor Market: Implications for Employment and Earnings, Center for American Progress, [Online] $<$ http://economics.mit.edu/files/5554>[Truy cập ngày 07.6.2019]

[8] David Autor \& Anna Salomons (2017), Does Productivity Growth Threaten Employment?, [Online] $<$ https://pdfs.semanticscholar.org/107b/63fb2e6794dafe06f9cb056f82c1093253d8.pdf>[Truy cập ngày 12.4.2019]

[9] Daron Acemoglu, David Autor (2011), Chapter 12 - Skills, Tasks and Technologies: Implications for Employment and Earning, Handbook of Labor Economics, 4(B), 1043-1171, [Online] $<$ https://economics.mit.edu/files/7006> [Truy cập ngày 30.6.2018]

[10] Goos, Maarten (2013), How the world of work is changing: a review of the evidence, [Online]<https://lirias.kuleuven.be/bitstream/123456789/446805/2/HowtheWorld.pdf $>$ \{Truy cập ngày 16.10.2018]

[11] Goos, Maarten, Manning, Alan and Salomons, Anna (2014), Explaining job polarization: routinebiased technological change and offshoring. American Economic Review, 104 (8). pp. 2509-2526. ISSN 0002-8282

[12] Greg C. Wright \& Paul Gaggl (2015), A Short-Run View of What Computers Do: Evidence from a U.K. Tax Incentive. [Online]<www.skope.ox.ac.uk/wp-content/uploads/.../Gregory-Wright-Research-paper123.pdf $>$ [Truy cập ngày 01.6.2019]

[13] International Labour Organization (2012), International Standard Classification of Occupations 2008 (ISCO08): Structure, group definitions and correspondence tables,[Online]<https://www.ilo.org/wcmsp5/groups/public/@dgreports/@dcomm/@publ/documents/public ation/wcms_172572.pdf $>$ [Truy cập ngày 01.06.2019]

[14] James Bessen (2019), Automation and Jobs: When Technology boost employment, [Online]<http://www.bu.edu/law/faculty-scholarship/working-paper-series> [Truy cập ngày 01.6.2019]

[15] James Bessen (2015), How computer automation affects ocupations: technology, jobs, and skills, [Online]<http://www.bu.edu/law/faculty/scholarship/workingpapers/2015.html> [Truy cập ngày 01.6.2019]

[16] Klaus Schwab ( 2016), The Fourth Industrial Revolution,World Economic Forum

[17] Klaus Schwab, Richard Samans (2016), The Future of Jobs - Employment, Skills and Workforce Strategy for the Fourth Industrial Revolution, World Economic Forum, [Online]<http://www.ilo.org/public/libdoc/nonigo/2016/490116.pdf> [Truy cập ngày 01.6.2019]

Karen Harris, Austin Kimson \& Andrew Schwedel (2018), Labor 2030: The Collision of Demographics, Automation and Inequality,[Online] <https://www.bain.com/insights/labor-2030-the-collision-ofdemographics-automation-and-inequality>[Truy cập ngày 07.6.2019] 
[19] McKinsey \& Company (2017), Jobs lost, jobs gained: Workforce Transitions in a Time of Automation,

Global

Institute

(MGI), [Online]<https://www.mckinsey.com/ /media/mckinsey/featured\%20insights/Future\%20of\%20Organizatio ns/What $\% 20$ the $\% 20$ future $\% 20$ of $\% 20$ work\%20will $\% 20$ mean $\% 20$ for $\% 20$ jobs $\% 20$ skills $\% 20$ and $\% 20$ wages/ MGI-Jobs-Lost-Jobs-Gained-Report-December-6-2017.ashx> [Truy cập ngày 01.6.2019]

[20] Nedelkoska, L. and G. Quintini (2018), Automation, skills use and training, OECD Social, Employment and Migration Working Papers, No. 202, OECD Publishing, Paris. [Online] $<$ http://pmb.cereq.fr/doc_num.php?explnum_id=4268>[Truy cập ngày 12.4.2019]

[21] Pwc (2018), Will robots really steal our jobs? An international analysis of the potential long-term impact of automation,

[Online]<https://www.pwc.com/hu/hu/kiadvanyok/assets/pdf/impact_of_automation_on_jobs.pdf> [Truy cập ngày 01.6.2019]

[22] Quincy Larson (2017), A warning from Bill Gates, Elon Musk, and Stephen Hawking, <https://www.freecodecamp.org/news/bill-gates-and-elon-musk-just-warned-us-about-the-one-thingpoliticians-are-too-scared-to-talk-8db9815fd398/>

[23] Shook, Ellyn \& Mark Knickrehm (2017), Harnessing Revolution: Creating the Future Workforce, Accenture Strategy, [Online]<https://www.accenture.com/_acnmedia/PDF40/Accenture-Strategy-Harnessing-Revolution-POV.pdf $>$ [Truy cập ngày 01.4.2019]

[24] Terry Gregory, Anna Salomons, Ulrich Zierahn (2016), Racing With or Against the Machine? Evidence from Europe, [Online]<http://ftp.zew.de/pub/zew-docs/dp/dp16053.pdf> [Truy cập ngày 01.6.2019]

[25] Tổng cục Thống kê Việt nam GSO, http://www.gso.gov.vn

[26] World Economic Forum (2017), Realizing Human Potential in the Fourth Industrial Revolution An Agenda for Leaders to shape the Future of Education, Gender and Work, [Online]<http://www3.weforum.org/docs/WEF_EGW_Whitepaper.pdf> [Truy cập ngày 01.6.2019]

World Economic Forum (2018), The Future of Jobs Report 2018 - Centre for the New Economy and Society, [Online]<http://www3.weforum.org/docs/WEF_Future_of_Jobs_2018.pdf $>$ [Truy cập ngày 01.6.2019]

[28] World Economic Forum (2018),Eight Futures of Work Scenarios and their Implications, WEF White paper,[Online] <http://www3.weforum.org/docs/WEF_FOW_Eight_Futures.pdf > [Truy cập ngày 12.4.2019]

[29] Wojciech Hardy, Piotr Lewandowski, Albert Park \& Du Yang (2018), The Global distribution of routine and non-routine [Online] <http://conference.iza.org/conference_files/WoLabConf_2018/lewandowski_p9882.pdf> [Truy cập ngày 06.2.2019]

Ngày nhận bài: 11/06/2019

Ngày chấp nhận đăng: 20/06/2019 